\title{
O Potencial dos Filmes na Formação de Valores Sustentáveis de Educadores
}

\author{
The Potential of Films in Formation of Educators' Sustainable Values
}

\author{
El Potencial de las Películas en la Formación de los Valores Sostenibles de los \\ Educadores
}

\author{
Ivana de Campos Ribeiro ${ }^{1}$ \\ Gisele Maria Schwartz ${ }^{2}$
}

\begin{abstract}
Resumo
Tendo em vista o cenário socioambiental atual, que fomenta a adoção de valores que colaboram para a insustentabilidade socioambiental, este estudo de natureza exploratória investigou a educação em valores, a qual pode colaborar para a sustentabilidade integral. Para tanto, realizou uma formação a distância a partir de um grupo fechado de uma rede social (Facebook). O objetivo era avaliar o potencial de filmes como promotores de mudanças de valores e virtudes. Para a avaliação dessas mudanças, foi utilizado o Questionário FIS - Felicidade Interna Sustentável e um questionário de avaliação final. Os resultados apontaram a melhoria em quase todos os domínios, destacando-se os maiores índices para Saúde e vitalidade: 8,73\% e Bem-estar psicológico: 7,44\%; e os menores índices para Padrão de vida e meio ambiente: 3,82\% e Relações humanas: 0,30\%. Ficou evidente que, em termos ambientais, mudanças têm início no âmbito biopsíquico, estimulando valores e virtudes e apontando a importância dessas dimensões como caminho para sociedades felizes e sustentáveis.
\end{abstract}

Palavras-chave: Filmes. Valores. Sustentabilidade.

\begin{abstract}
Considering that the current environmental scenario has promoted the adoption of values that contribute to the socio-environmental unsustainability, this exploratory nature study aimed at the education in values, which can contribute to the integral sustainability. Therefore, a distance education training was carried out from a closed group on a social network (Facebook $\AA)$. The objective was to evaluate the potential of films as promoters of values and virtues changes. To assess these possible changes, we used the FIS Questionnaire (Sustainable Internal Happiness) and a final evaluation questionnaire. The results showed an improvement in almost all areas, especially the highest rates for Health and Vitality: 8,73\% and Psychological well-being: 7,44\%; and the lowest rates for Standard of Living and Environment: 3,82\%; and Human Relations: 0,30\%. It became evident that, in environmental terms, the changes begin within a biopsychic dimension, stimulating values and virtues, and pointing out the importance of these dimensions as a way to happy and sustainable societies.
\end{abstract}

Keywords: Movies. Values. Sustainability.

\section{Resumen}

Teniendo en cuenta que el escenario ambiental actual ha impulsado la adopción de valores que contribuyen a la falta de sostenibilidad socioambiental, este estudio de carácter exploratorio investigó la educación con valores, que puede contribuir a la sostenibilidad integral. Para este propósito, una formación de educación a distancia se ha desarrollado a partir de un grupo cerrado en una Red Social (Facebook®). El objetivo fue evaluar el potencial de las películas tales como promotoras de cambios de valores y virtudes. Para evaluar estos posibles cambios, se utilizó el Cuestionario FIS - Felicidad Interna Sostenible y un cuestionario de evaluación final. Los resultados mostraron una mejora en casi todas las áreas, con destaque a las tasas más altas para la salud y vitalidad: $8,73 \%$ y Psicología y Bienestar: 7,44\%; y aun, las tasas más bajas para los Patrones de Vida y el Medio Ambiente: 3,82\%; y para las Relaciones Humanas: 0,30\%. Se hizo evidente que, en términos ambientales, el cambio comienza em la dimensión biosíquica, estimulando valores y virtudes, y señalando la importancia de estas dimensiones como camino a sociedades felices y sostenibles.

\footnotetext{
${ }^{1}$ Doutora em Ecologia e Recursos Naturais (Um. Federal de São Carlos) e Pós doutora em Desenvolvimento Humano e Tecnologias (UNESP-Rio Claro). E-mail: ivana.ibev@ gmail.com

${ }^{2}$ Doutora em Psicologia Escolar e do Desenvolvimento Humano (Universidade de São Paulo). E-mail: schwartz@rc.unesp.br
} 
Palabras clave: Películas. Los valores. Sostenibilidad.

\section{Introdução}

Os meios de comunicação de massa e, posteriormente, as tecnologias de informação e comunicação transformaram o planeta na "aldeia global" vislumbrada por Marshall McLuhan (1962), onde a interdependência eletrônica poderia recriar a imagem de uma aldeia, a qual transformaria a cultura, levando a população mundial a uma identidade coletiva, na qual as culturas e tradições passariam do domínio regional para o global. Essa interação é rica, não apenas em seu aspecto cultural, mas também como geradora de uma ética planetária.

Como lembra Moreno (2013, p. 61), embora McLuhan tivesse escrito antes da criação da world wide web, "é possível analisar as suas teses principais à luz dos desenvolvimentos actuais das tecnologias de comunicação e informação e dos usos sociais que delas são feitos". Considerando-se, de um lado, a internet como uma tecnologia de comunicação recente e, de outro, os filmes, cuja tecnologia foi desenvolvida pelos irmãos franceses Louis e Auguste Lumière em 1895, sendo possível concluir que essas tecnologias estão hoje associadas, pois os filmes podem ser apreciados em casa.

Não temos dúvidas de que a internet trouxe inúmeros benefícios, mas também provocou incômodos e impactos. A utilização massiva dela deu origem a formas distorcidas, entre as quais a dependência dessas tecnologias como forma de inclusão social, fomentando a superficialidade, o consumo e - por que não? - formas escusas de comportamentos, inspirando valores distorcidos. Neste sentido, qual seria o papel do educador/educador ambiental? Como valer-se dessas tecnologias para proporcionar experiências capazes de levar alunos e sujeitos à reflexão sobre o mundo em que vivem? Os filmes, enquanto recurso tecnológico, sempre estiveram disponíveis aos educadores/educadores ambientais, mas teriam também papel significativo na propagação de valores sustentáveis que poderiam reverberar positivamente em seus alunos?

\section{As tecnologias, a educação e os valores humanos}

Ao iniciar seu livro Tecnologia e educação, Ladislau Dowbor (2013) coloca em destaque uma mensagem encontrada em um campo de concentração nazista, após o fim da Segunda Guerra Mundial. A carta era endereçada a professores e versava sobre as barbáries impostas por homens e mulheres letrados a outros homens, mulheres e crianças. A respeito desse episódio, diz Dowbor (2013, p. 5),

tenho minhas suspeitas sobre a Educação. Meu pedido é: ajude seus alunos a tornarem-se humanos. Seus esforços nunca deverão produzir monstros treinados ou psicopatas hábeis. Ler, escrever e aritmética só são importantes para fazer nossas crianças mais humanas.

Neste sentido, não basta hoje trabalhar com propostas de modernização da Educação, mas de repensar (ou ressignificar) a dinâmica do conhecimento em seu sentido mais amplo, destacando as novas funções do educador como mediador desse processo. Há de se considerar ainda que a educação em sentido lato deveria conter desde a educação moral até a ambiental, afinal não se pode estabelecer limites para a educação, a qual deveria ser para a vida e com valores condizentes com sociedades felizes e sustentáveis, perpassando as disciplinas até a formação profissional.

Contudo, o sistema em que estamos inseridos produz um modo de vida insustentável, quer no plano das relações do indivíduo consigo próprio, quer nas relações humanas e nos modos de vida, os quais, consequentemente, afetam os recursos, ou melhor, os bens naturais, 
como é o caso do consumo (ORTIGOSA; LOMBARDO, 2011; RIBEIRO, 2005). Esse comportamento é, na maior parte das vezes, retroalimentado pelos meios de comunicação (LINS; CAVALCANTI; FARIA, 2011; MORAES; ESCOTT; PIZZATO, 2011). Neste sentido, o conhecimento acerca da subjetividade humana não pode prescindir de ações nas quais o foco está no comportamento humano e nas mudanças comportamentais. Os meios estão à nossa disposição para serem usados sustentável ou insustentavelmente.

Sendo assim, este texto busca tecer argumentações que sustentam o propósito de construção de sociedades sustentáveis (RUSCHEINSKY, 2010), tendo como pano de fundo a sustentabilidade nos níveis biopsíquico, social e perante a natureza, cujas bases, pode-se afirmar, se assentam nos valores humanos. No processo de cooperação entre saberes, buscamse olhares interdisciplinares que vislumbrem caminhos para a formação de educadores/educadores ambientais, nos quais prevaleçam valores que conduzam a uma vida harmônica, na qual regras de convivência se estabeleçam e abracem tanto as relações humanas quanto os meios onde elas se dão, como ambientes familiares, de estudo e trabalho, bairros, cidades, entre outros.

Ribeiro (2010) relata que, ao longo de mais de quinze anos dedicados à pesquisa e à intervenção com educadores, percebeu que nem sempre os estes possuíam valores condizentes com a promoção da sustentabilidade, porque os observava em estados de desarmonia interna ou com dificuldade para o trabalho grupal, o que se expressava no excesso de irritação ou apatia, os quais podem influenciar significativamente na motivação para ações pró-ambientais. Afinal, como estimular valores que conduzam a um ideal de sustentabilidade integral, quando os valores individuais necessitam ser revistos ou consolidados? Estes questionamentos impulsionaram a busca por uma linguagem que, para além das formações baseadas na transferência de informações sobre a produção científica acerca da relação educação-valoressustentabilidade, pudesse levá-los a refletir sobre seus próprios valores, auxiliar a ajustá-los quando necessário e, na medida do possível, conduzir a formas mais harmônicas de viver.

No sentido da sustentabilidade integral, o trabalho com valores pode impulsionar uma nova percepção, postura e contribuição das Tecnologias da Informação e Comunicação (TIC), já que uma formação como Educação à Distância $(\mathrm{EaD})$ pode evidenciar o papel do cinema, avaliando sua colaboração de maneira mais efetiva. Para Dowbor (2013, p. 16, grifos do autor), tudo indica que não estamos enfrentando apenas uma revolução tecnológica. Na realidade, o conjunto de transformações parece estar levando a uma sinergia da comunicação, informação e formação, criando uma realidade nova, que está sendo designada como "sociedade do conhecimento". De certo modo, o processo reflete os primeiros passos do homo culturalis, em contraposição ao homo economicus dos séculos XIX e XX.

Espera-se que o conhecimento não ocupe apenas o intelecto dos usuários, mas que possa ser explorado e que esse homo culturalis possa emergir carregado de valores que o façam se diferenciar do homo economicus, restrito a uma vida baseada no consumo e carregada de influências hedônicas, cujas fontes de felicidade estão voltadas ao prazer material e cuja consequência está refletida num mundo de insustentabilidades, onde os meios de comunicação têm papel medular na sustentação do status quo. Cabe àqueles que, conscientes do seu papel na transformação social ou na fecundação desse homo culturalis, explorem tais meios de maneira a inocular, especialmente nas gerações mais suscetíveis à assimilação de informações, padrões culturais do comportamento humano e valores que garantam uma vida feliz e sustentável. Esse papel é especialmente recomendado para educadores, ambientais ou não, dada a sua emergência e relevância, uma vez que a velocidade das produções dos que alimentam e preservam o homo economicus é substancial e acelerada em comparação com a acanhada criação de produtos e ações que têm como função mitigar o aspecto corrosivo do sistema atual de valores. 


\section{Um caminho para as sociedades sustentáveis}

Entre os trabalhos pioneiros sobre o tema, encontra-se o de Trajber e Costa (2001), que é dedicado à avaliação de produções específicas para a Educação Ambiental. São poucos os trabalhos que avaliam as produções videográficas e cinematográficas, com conteúdos aplicados à Educação Ambiental, entre eles, há o estudo de Zan Vieira e Rosso (2011), que avalia o potencial das produções voltadas à Educação Ambiental, e o de Viteri, Clarebout e Crauwels (2014), que envolve o nível de recordação e motivação sobre este tipo de material paradidático, com alunos de quinta série do ensino fundamental. Outros exemplos mais recentes podem ser citados, como o de Marques e Reis (2017), que analisa os efeitos da difusão de informações a partir de vídeos digitais sobre o tema da poluição ambiental e as percepções dos alunos de 12 a 13 anos, e o de Ferreira e Limberger (2017) sobre a sensibilização dos alunos das escolas municipais e estaduais quanto à preservação dos butiazais.

Entretanto, no caminho para uma Educação Ambiental que possa superar a perpetuação do homo economicus, o qual se volta exclusivamente para os prazeres do mundo material, estaria a disseminação da consciência sobre os verdadeiros valores, não excluindo os prazeres e necessidades da matéria, mas buscando uma vida sustentável, focalizada nas verdadeiras necessidades do ser humano, no ponto de equilíbrio entre o supérfluo e o necessário, entre a aparência e a ostentação, criticando esse mundo insustentável e de ilusão.

O investimento em valores sustentáveis é uma prática da Educação Ambiental, a qual, nos últimos anos, vem se ocupando de dimensões mais subjetivas do viver humano como caminho para a felicidade (ALVES; SORRENTINO, 2010; BONOTTO; CARVALHO, 2016). Contudo, as produções científicas são voltadas aos alunos, como se os educadores já estivessem virtuosamente prontos e aptos para o trabalho com tais valores ou como se fossem simples transmissores de informações. Nesse sentido, Fraga e Bonotto (2016, p. 50-51) questionam "se olhar para nossos valores é algo muito difícil para nós, educadores, como seria possível trabalhar esses aspectos com nossos(as) alunos(as)?". São raros os casos em que as pesquisas se dedicam à formação do caráter do educador, do seu bem-estar ou da sua felicidade.

Ryan Niemiec ${ }^{2}$ e Danny Wedding (2013) vêm se dedicando a investigações sobre os pontos fortes do caráter e da consciência a partir da avaliação de filmes que podem oferecer possibilidades de reflexão e autoconhecimento a educadores/educadores ambientais, com vistas ao aperfeiçoamento dos seus valores e virtudes. Baseando-se nas seis virtudes encontradas em mais de duzentos catálogos que abrangem mais de 3 mil anos, Peterson e Seligman (2004) estudaram desde a filosofia de Aristóteles, passando pelos textos de Benjamim Franklin até os códigos samurais. As virtudes coragem, humanidade, transcendência, temperança, justiça, sabedoria e conhecimento foram subdivididas em 24 qualidades humanas positivas (virtudes). Esse estudo é apresentado por Niemiec e Wedding em Character strengths and virtues, no qual classificam três níveis conceituais: virtudes, forças e temas situacionais. A primeira - a virtude - teria como característica principal o caráter universalista valorizado pelos filósofos morais e pensadores religiosos; a segunda - a força -é compreendida como os componentes psicológicos ou caminhos pelos quais as virtudes são mostradas; por fim, a terceira - os temas situacionais - é interpretada como as práticas ou caminhos que levam situações e pessoas a mostrarem suas forças (NIEMIEC; WEDDING, 2013, p. 23).

Vale, aqui, apresentar a relação entre valores e virtudes, e o motivo pelo qual Peterson e Seligman adotam as virtudes. Como já exposto, as virtudes têm caráter universal, uma vez que têm o mesmo significado para qualquer pessoa, em qualquer lugar do mundo e no tempo

\footnotetext{
${ }^{2}$ Diretor de Educação do Instituto Values in Action on Character, instituição considerada líder na área da Psicologia Positiva e líder mundial na ciência da força de caráter. O autor se dedica a pesquisas sobre a prática da força de caráter, o que inclui o seguimento da educação.
} 
histórico. Já os valores não têm esse caráter e, quando estimulados, fortalecem as virtudes. Quando os valores são distorcidos, ou seja, quando são indesejáveis e "negativos" conduzem a uma vida de insustentabilidades (RIBEIRO; SCHWARTZ, 2017), a exemplo do cuidado e do descaso, da prudência e da imprudência ou da cooperação e do egoísmo. No diálogo Fédon, Platão (1999) credita ao exercício das virtudes a purificação da alma. Essas são as bases da Educação Ambiental Profunda (EAP) (RIBEIRO, 2013), a qual considera a importância do autoconhecimento tão importante quanto o conhecimento das dinâmicas que regem a sociedade e a natureza (RIBEIRO; SCHWARTZ, 2017).

Niemiec e Wedding (2013) combinam as pesquisas na área da Psicologia Positiva e as mensagens que perpassam as tramas dos filmes com o intuito de melhorar a vida do sujeito. Neste sentido, os autores buscam avaliar e classificar filmes que toquem o mais profundo do ser, fazendo emergir virtudes que adentram a questão ambiental (a partir da virtude "cidadania"). As explicações claras e com grande profundidade científica têm como propósito exemplificar, esclarecer e inspirar o destinatário.

\section{Contribuições da Psicologia Positiva e dos filmes à Educação Ambiental}

Este estudo tem por objetivo investigar o potencial de filmes utilizados como instrumento paradidático (NIEMIEC; WEDDING, 2013) para a formação à distância de educadores e/ou educadores ambientais, com vistas à estimulação de virtudes e da força de caráter, elementos essenciais para a construção de sociedades felizes e sustentáveis, conforme apontado pelo Programa Nacional de Educação Ambiental: ProNEA (BRASIL, 2005).

O caráter interdisciplinar e a natureza quali-quantitativa delineiam este estudo porque se mostram adequados para investigação de fenômenos sociais. Seu caráter qualitativo está relacionado à avaliação do questionário adotado para coleta de dados, uma vez que contém afirmativas pontuadas em escala Lickert de cinco pontos (FAY; PROSCHAN, 2010) e está associado com o método qualitativo por comtemplar a oportunidade de obter informações contextuais (RICHARDSON, 2007), o que inclui a discussão dos dados encontrados à luz dos teóricos aqui abordados.

Para alcançar o objetivo proposto, este estudo se desenvolveu por meio de pesquisas bibliográfica e exploratória. A pesquisa bibliográfica utilizou fontes referenciais que ampliaram as discussões propostas. Uma das vantagens da pesquisa bibliográfica se refere ao fato de ela ter permitido a avaliação de uma vasta gama de fenômenos veiculados em artigos de periódicos, livros, teses, dissertações e sites disponíveis na internet (GIL, 2008). Já a pesquisa exploratória possibilitou a ampliação do conhecimento acerca de determinado assunto a partir da leitura de uma realidade específica, possibilitando a criação de hipóteses e contribuindo para estudos posteriores (MINAYO; SANCHES, 1993).

A formação compreendeu atividades à distância (formação $\mathrm{EaD}$ ) através da criação de um grupo fechado em uma rede social (Facebook). Suas atividades se estenderam por cinco meses. Aceitaram participar desta pesquisa, a princípio, cinquenta educadores/educadores ambientais do ensino fundamental, médio e superior, de países de língua portuguesa de vários estados do Brasil, Cabo Verde, Portugal e um participante de nacionalidade peruana, com português fluente. Porém, apenas quinze conseguiram concluir a formação. Os motivos variavam entre a falta de tempo para acompanhar o ritmo das postagens com as listas dos filmes, problemas de saúde ou familiares, entre outros. O convite foi realizado a partir de e-groups de Educação Ambiental e redes sociais. Vale lembrar que não houve quaisquer restrições quanto à faixa etária, sexo, cor/raça ou etnia, orientação sexual e identidade de gênero, classes e grupos sociais, uma vez que se pretendia atingir uma amostra diversificada, mas falante do português. Após a organização do grupo no Facebook, foram oferecidos documentos com orientações para a participação da formação EaD e o Termo de Consentimento Livre e Esclarecido. 
O propósito da formação, na qual não houve exposição teórica, era a troca de impressões, que aconteceram a partir dos comentários postados no grupo criado, "Filmes \& Valores Humanos: Educação Ambiental para Sociedades Sustentáveis"3, no qual as interações com os colegas podiam favorecer a visão expandida de cada filme e os valores trabalhados. Semanalmente, eram postadas listas com filmes, as quais eram organizadas a partir da força do caráter e das virtudes de Peterson e Seligman (2004). As seis forças de caráter foram reorganizadas e distribuídas em três módulos. Por sua vez, três dimensões foram trabalhadas na Educação Ambiental de Corpo\&Alma: indivíduo (dimensão biopsíquica), sociedade e natureza, dimensões que se inter-relacionam e que se influenciam reciprocamente (RIBEIRO, 2005; RIBEIRO; SCHWARTZ, 2017). As seis forças do caráter e as 24 virtudes de Peterson e Seligman (2004) foram assim organizadas:

Módulo 1: Sustentabilidade: dimensão das relações interiores (três meses):

Sabedoria: criatividade (originalidade, criatividade); curiosidade (recompensa, busca de novidades, abertura às experiências); mente aberta (discernimento, pensamento crítico); amor ao aprendizado (prendendo, perspectiva, sabedoria);

Coragem: bravura (valor); integridade (autenticidade, honestidade); vitalidade;

(entusiasmo, vigor, energia); persistência (perseverança, diligência);

Temperança (moderação): perdão e compaixão (misericórdia); humildade (modéstia); prudência e autorregulação;

Transcendência: apreciação da beleza e excelência (admiração, elevação); gratidão; esperança (otimismo, espírito futuro, orientação para o futuro); humor (brincadeira, jovialidade); espiritualidade (religiosidade, fé, finalidade, significado).

Exemplos de filmes: A vida é bela, Poder além da vida, O labirinto do fauno, Madame Curie, Monsieur Ibrahim, As aventuras de P $i$, A voz do coração, A noiva do cadáver, $O$ escafandro $e$ a borboleta, O caçador de pipas, Madre Teresa, Bakhita, Avatar, Fonte de vida e Gandhi.

Módulo 2 - Sustentabilidade: dimensão das relações sociais (um mês):

Humanidade: social inteligência (emocional, inteligência pessoal); amor; bondade (generosidade, nutrição, cuidado, compaixão, amor altruísta, amabilidade);

Exemplos de filmes: K-Pax, A caminho da luz, Conduzindo Miss Dayse, A garçonete, Casablanca, A corrente do bem, Luzes da cidade, O fabuloso destino de Amélie Poulain, A copa e Bagdá café.

Módulo 3 - Sustentabilidade: dimensão das questões ambientais (um mês):

Justiça: cidadania (responsabilidade social, lealdade, trabalho em equipe); equidade; liderança; Exemplos de filmes: A marcha dos pinguins, $O$ milagre veio do espaço, Gandhi, Muito além do jardim, Contrastes humanos, Dança com os lobos, Erin Brockovich, Jornada pela liberdade, Os delírios de consumo de Becky Bloom.

As listas de filmes avaliados por Niemiec e Wedding (2013) continham, em média, oito longas-metragens com sinopses, imagem da capa do DVD e link para que fossem assistidos online, podendo o participante escolhê-los de acordo com seus critérios. Foram priorizados os títulos classificados pelos autores com três a cinco "psi" ( $\Psi$ símbolo da Psicologia), os quais trabalhavam várias virtudes. As classificações iam de um a cinco $\Psi$.

O instrumento utilizado para a avaliação do potencial desses filmes para repensar valores e virtudes foi o FIS - Felicidade Interna Sustentável, questionário desenvolvido e validado por Ribeiro e Schwartz (2014), o qual avalia valores, atitudes e ações dos participantes.

\footnotetext{
${ }^{3}$ https://bit.ly/2MOLNoa.
} 
O questionário foi aplicado de forma bifásica, antes do início da formação e após sua conclusão. Os dados foram agrupados de acordo com seis domínios: Bem-estar psicológico; Saúde e vitalidade; Educação, cultura e religião; Relações humanas; e Padrão de vida e meio ambiente. Aplicamos ainda um questionário de avaliação final da experiência com questões abertas.

Com o objetivo de constatar o aumento nas pontuações das respostas dos indivíduos aos questionários para cada domínio, foram realizados testes de comparação antes e depois, considerando-se como hipótese nula que a média das respostas antes e depois seria igual e, como hipótese alternativa, que a média das respostas após a intervenção seria melhor do que a anterior. No que diz respeito ao teste de hipóteses, foi usado o teste de Wilcoxon-MannWhitney (FAY; PROSCHAN, 2010), considerando-se 5\% de significância. Considerou-se as respostas pareadas, uma vez que os respondentes antes e depois eram os mesmos. Vale lembrar que a diferença entre o número de participantes antes e depois foi superada pelo modelo estatístico adotado.

Incialmente foi realizada a análise descritiva dos dados, a fim de obter melhor percepção sobre as possíveis mudanças positivas no rol de virtudes e valores dos participantes. Como o intuito era comparar o antes e o depois nas respostas, optou-se pela apresentação de uma tabela contendo a média e o desvio-padrão antes e depois para cada domínio e as médias em âmbito geral.

Tabela 1 - Média e desvio-padrão para respostas antes e depois da formação

\begin{tabular}{|c|c|c|c|c|c|}
\hline Domínio & $\begin{array}{c}\text { Média } \\
\text { antes }\end{array}$ & $\begin{array}{c}\text { Média } \\
\text { depois }\end{array}$ & $\begin{array}{c}\text { \% de } \\
\text { melhoria } \\
\text { média }\end{array}$ & $\begin{array}{c}\text { DP } \\
\text { antes }\end{array}$ & $\begin{array}{c}\text { DP } \\
\text { depois }\end{array}$ \\
\hline $\begin{array}{c}\text { Bem-estar } \\
\text { psicológico }\end{array}$ & 3.667 & 3.939 & $7,44 \%$ & 0.461 & 0.564 \\
\hline Saúde e vitalidade & 3.667 & 3.986 & $8,73 \%$ & 0.728 & 0.528 \\
\hline $\begin{array}{c}\text { Educação, cultura } \\
\text { e religião }\end{array}$ & 3.951 & 4.102 & $3,82 \%$ & 0.527 & 0.527 \\
\hline $\begin{array}{c}\text { Relações } \\
\text { humanas }\end{array}$ & 3.650 & 3.661 & $0,30 \%$ & 0.441 & 0.442 \\
\hline $\begin{array}{c}\text { Padrão de vida e } \\
\text { meio ambiente }\end{array}$ & 3.987 & 4.120 & $3,34 \%$ & 0.380 & 0.419 \\
\hline $\begin{array}{c}\text { Geral (todas as } \\
\text { dimensões) }\end{array}$ & 3.786 & 3.970 & $4,85 \%$ & 0.346 & 0.426 \\
\hline
\end{tabular}

Quanto ao teste de hipóteses, vemos que, para a dimensão Bem-estar psicológico, a melhoria nas respostas foi notória. A hipótese de igualdade de médias é rejeitada, havendo evidências estatísticas de que, de fato, a intervenção influenciou a melhoria dessa dimensão (valor $\mathrm{p}=0.022$ ). Para a dimensão Saúde e vitalidade também houve melhoria significativa (valor p=0.019). Para a dimensão Educação, cultura e religião, apesar de ter havido $3,82 \%$ de melhoria média, a melhoria não foi estatisticamente significativa a 5\% de significância (valor $\mathrm{p}=0.104$ ). A dimensão Relações humanas foi a que menos influência sofreu, havendo melhoria média nas respostas de apenas $0,30 \%$, não sendo, portanto, estatisticamente diferente (valor $\mathrm{p}=0.29$ ). Para a dimensão Padrão de vida e meio ambiente a $5 \%$ de significância, não há diferença estatística (valor $\mathrm{p}=0.097$ ). É interessante notar que, se levássemos em conta $10 \%$ de significância, sendo então o teste menos rigoroso, haveria diferença significativa. Em seguida, buscou-se interpretar os resultados de cada domínio à luz do referencial teórico, explorando, ainda, os comentários dos participantes no questionário final com questões abertas. 


\subsection{Bem-estar psicológico}

O aumento de 7,44\% dessa dimensão reflete o avanço no sentido do autoconhecimento. Considerando-se o tempo de intervenção (cinco meses), pode-se dizer que os filmes tiveram papel relevante nesse processo. Os dados apontam a variação no sentido do aumento de valores positivos ou sustentáveis.

Nesta dimensão a sustentabilidade está voltada para a interioridade de cada indivíduo, especialmente para as influências da alma (psique). Ao buscar nos comentários dos participantes a relação entre os valores explorados pelos filmes e o modo como viam a experiência com relação ao bem-estar psicológico e sua intrínseca relação com a autotransformação, lia-se, por exemplo, "os filmes conseguem tocar as pessoas no fundo, seja pela emoção, seja pelo bom exemplo. Acredito que os filmes, atrelados às práticas educativas, possuem capacidade de promover a autotransformação" (E10), o que comprova que os filmes acessaram as subjetividades, levando à auto-observação e, posteriormente, à autotransformação. Ou, ainda, "como uma forma de se apropriar (de valores) e colocar em ação, transformações e sentimentos adormecidos e que foram trazidos à tona de uma forma lúdica". Nesse depoimento, os filmes parecem despertar valores já existentes e esquecidos.

Quanto ao bem-estar psicológico despertado por filmes como A vida é bela, A voz do coração ou mesmo Avatar, pode-se dizer que eles mostram que, quando desperta para a sua essência, o ser humano começa a se questionar com perguntas de cunho existencial. Em contato com filmes, situações e personagens que promovem o resgate de valores adormecidos, o indivíduo acaba por tomar consciência da necessidade de agir sempre corretamente e de acordo com as virtudes que compõem o seu caráter, o qual revela um estado de paz interior necessário para fomentar o fluir dessas virtudes, permeando todas as dimensões da existência humana, do interior para o exterior e do mais íntimo para as relações socioambientais (MARTINELLI, 1999; O’BRIEN, 2012).

\subsection{Saúde e vitalidade}

Esta dimensão foi a que apresentou maior índice de mudança: 8,73\%. Para discorrer sobre os fatores que levaram a este índice, deve-se partir de hipóteses que encaminhem a busca por publicações que ajudem a compreendê-los. Quais seriam os fatores que levaram os indivíduos a alterarem positivamente sua relação com o corpo e o bem-estar psicológico a partir da reflexão originada de filmes? Não há estudos específicos que possam responder a esta questão, embora haja possibilidades de tecer relações entre a felicidade autêntica, a saúde e o bem-estar ou vitalidade, sentimentos que, mesmo de forma sutil, são tocados em filmes como Poder além da vida, K-Pax e $O$ escafandro e a borboleta.

Segundo o depoimento de um participante, "quando nos abrimos para o aprendizado e assumimos com coragem a vida, acessamos diferentes recursos (terapias, dinâmicas...) que auxiliam na mudança. Necessariamente, pau que nasce torto pode se endireitar, com disciplina, coragem e muita vontade" (E4). Trata-se de um exemplo de que as mudanças relacionadas a questões práticas, como a saúde e a vitalidade, são alvos de mudanças mais fáceis, mais próximas e de maior interesse do eu, ou "self", diferentemente das mudanças internas ou de comportamento socioambiental. Mostrando o quanto o ser humano ainda está focado nas coisas da matéria, mesmo que seja representada pelo corpo.

Com relação a esse tema, Myers (2004) dedica um capítulo ao "Estresse, saúde e florescimento humano", estabelecendo relações e estudando como as emoções e a personalidade influenciam o risco de doença, os efeitos do stress e a promoção de uma vida 
mais saudável, sugerindo a existência de motivações, mesmo que inconscientemente, para a incorporação de comportamentos sustentáveis no que tange à saúde e à vitalidade.

Myers (2004) considera que pessoas felizes vivem de forma mais saudável e satisfatoriamente e lembra, ainda, que a felicidade aumenta a percepção do mundo e a vontade de ajudar os outros, um ato representativo do florescimento humano. Estas pessoas estariam longe do estresse e mais próximas de uma vida saudável, o que inegavelmente interfere no humor, nas relações sociais e com a natureza. Neste sentido, os filmes e seus personagens servem de exemplo de superação.

\subsection{Educação, cultura e religião}

Considerando-se a hipótese de uma espiral de interesses, dos centrais aos mais periféricos, pode-se considerar que as esferas atingidas por ela, ao alcançar essa dimensão, exige mais tempo de reflexão, autoconhecimento e autotransformação. O índice de 3,82\%, considerado o tempo de intervenção e o percurso da ação dessa espiral, demonstra o papel dos filmes no resgate e na potencialização de virtudes e valores que envolvem a sustentabilidade no âmbito social, podendo, inclusive, ser mais bem utilizados no ensino em diferentes níveis, a exemplo do trabalho de Blasco et al. (2005) com relação à importância do cinema na formação humanista de médicos.

Um dos participantes escreveu sobre o filme Lendas da vida: "acho que um personagem que eu nunca esquecerei será Bagger Vance, [...] justamente pelo poder que demonstrou de influenciar para o bem a vida dos outros"(E4). Neste sentido, filmes como Bakhita, Avatar, Escola da vida ou $O$ caçador de pipas também evidenciam comportamentos impulsionados por valores e virtudes, como bem ilustrado por este participante, "quando a experiência da personagem desencadeia um movimento interno, é preciso dar tempo, deixar entrar, deixar que a ideia desça da cabeça ao coração para tornar-se um detonador da autotransformação" (E2).

Para Araújo e Puig (2007), a formação de valores é uma meta importante a ser alcançada pelas instituições de ensino. Eles propõem como caminho possível a compreensão da realidade psíquica humana e suas diferentes formas de relacionamentos interpsíquicos, os quais envolvem o âmbito natural, social e cultural, e os intrapsíquicos, que envolve o autoconhecimento, pois ambos ampliam as estratégias de intervenção direta na realidade social.

Para Silva (2013), atos violentos e guerras ainda são travadas por ausência de virtudes imprescindíveis, por exemplo a paz, a sustentabilidade social e a tolerância, que não se revela a não ser por virtudes como o respeito, a imparcialidade e o amor. O conceito de tolerância aqui apresentado, mais próximo das virtudes humanas, é um aspecto positivos da personalidade humana, como defende a Psicologia Positiva.

\subsection{Relações humanas}

Entre os cinco domínios, as relações humanas foram as que apresentaram menor índice de mudanças, apenas $0,30 \%$. O que explicaria alteração tão insignificativa? Buscamos as respostas na obra de Carl Gustav Jung. Segundo Jung (1992), uma natureza sombria foi legada à humanidade ao longo de sua jornada evolutiva. Jung define este lado sombrio como aquilo que uma pessoa não tem desejo de ser, ou seja, o lado negativo da personalidade e no qual residem as qualidades desagradáveis e primitivas da natureza humana (ZWEIG; ABRAMS, 2002), que não deseja "ver" refletida no outro, seja humano seja personagem. É no outro que o humano vê a si próprio, o que Jung (1992) chama de "efeito espelho". Isso significa que tudo aquilo que vê nos outros é apenas o próprio reflexo, especialmente aquilo que não gosta ou critica (ODOUL, 2003). As dificuldades no trato com o outro refletem padrões (e sempre 
envolvem valores e virtudes) que necessitam ser trabalhados para que as relações sejam felizes e sustentáveis.

É no campo das inter-relações que o exercício de virtudes como o altruísmo e tolerância são praticados, de acordo com o estudo de Turner, Barling e Zacharatos (2002). Esses estudiosos apontam a prática do altruísmo como responsável pela intensificação de estados de bem-estar no caminho para a harmonia entre seres, individualmente e em seus grupos, e como forma de correção de conduta. Dessa forma, o comentário "percebo em mim mesmo que sempre havia campos da minha vida em que eu poderia trabalhar para melhorá-los, mas que por não meditar profundamente na necessidade de mudança eu continuava a agir ou pensar de maneira negativa" (E3), mostra como os filmes têm a capacidade de tocar a alma, fazer refletir e repensar valores e atitudes, independentemente de o espelho refletido ter valores distorcidos ou positivos. Filmes como Conduzindo Miss Dayse, A garçonete, A corrente do bem, O fabuloso destino de Amélie Poulain ou Bakhita são exemplos de como o comportamento dos personagens inspiram mudanças de valores e atitudes.

Percebe-se que virtudes como o perdão, a tolerância e o respeito, que são indispensáveis para a construção de sociedades sustentáveis, necessitam da consciência sobre si e das dinâmicas que regem a psique humana, por isso, "o filme chega como informação de um pensamento ou hábito novo, abrindo possibilidades" (comentário de participante).

\subsection{Padrão de vida e meio ambiente}

Outro aspecto tão complexo quanto às relações humanas é o padrão de vida e seus reflexos no meio ambiente. Contudo, considerando-se o modelo da espiral, esse domínio obteve considerável índice de mudança, 3,34\%. Tão complexas quanto as transformações na relação com o outro são as mudanças que exigem alterações no padrão de vida, uma vez que hoje são raros os que abrem mão, por exemplo, dos seus padrões de consumo em benefício do meio ambiente. São reflexos da disseminação de um padrão de felicidade hedônica e baseado nos prazeres materiais, para além das necessidades reais e sendo promotores de uma felicidade insustentável (RIBEIRO; SCHWARRZ, 2017).

Filmes como Dança com lobos, Erin Brockovich, Jornada pela liberdade, Avatar ou ainda Os delírios de consumo de Becky Bloom estimulam as mudanças em relação ao dever para com o outro e a natureza. Comenta um dos participantes, "no dia a dia, para mim tem a ver com o estimulo que dá, observar as histórias destes personagens grandiosos, sendo que você fica com a vontade de agir como eles, aprender e repetir as coisas boas que fazem, imitar os valores e virtudes que evocam" (E1), ou ainda, "eu senti muita admiração por vários dos personagens que até cheguei a senti-los como heróis, pessoas que queria seguir. E me senti tocada por tantas situações diferentes, de forma pessoal ou não. É aí quando você reage, quando sente que mexe no coração" (E8). E isso faz com que a mensagem seja assimilada com muito mais intensidade, uma vez que é armazenada no sistema límbico, cujas memórias são a garantia de motivação para repensar ações cotidianas (RIBEIRO; SCHWARTZ, 2017).

\section{Conclusão}

O papel do educador/educadora ambiental ainda pode ser considerado em relação à conscientização. Contudo, no sentido da busca pela consciência de si próprio como propõe a EA Profunda (RIBEIRO, 2013), em que o reencontro consigo é inerente ao ser humano, independentemente do nível de percepção sobre essa necessidade, é um caminho que pode ser trabalhado desde o mais profundo do ser.

Neste sentido, as tecnologias de informação e comunicação (TIC) ganham cada vez mais elementos para tornar o planeta numa pequena aldeia, da forma que McLuhan (1962) sonharia. 
É o mundo das crianças, dos jovens e dos adultos e seus acessórios tecnológicos. E, independentemente da tecnologia utilizada para acessar, os filmes ainda encantam todas as faixas etárias, podendo e devendo ser mais explorados em casa, em empresas, nas escolas ou comunidades.

Os filmes saíram das telas do cinema para as TVs, tablets, celulares e continuam encantando multidões, restando apenas explorar todo poder que têm para impactar mentes e corações. Entretanto, entre tantas produções que nada acrescentam ou que, pior, incitam valores distorcidos, estes instrumentos já apontaram sua eficácia para a construção (e não desconstrução) do caráter, como comprovou esta pesquisa e as demais citadas, de forma que na Educação Ambiental eles devem ser explorados para proporcionar experiências capazes de levar os alunos à reflexão sobre o mundo onde vivem e sobre a importância de suas escolhas, desde as internas (da alma) e físicas (saúde) às sociais e ambientais, tendo em mente e no coração que essas escolhas levam à sustentabilidade ou à insustentabilidade.

Portanto, pode-se concluir que, sim, os filmes, enquanto recursos tecnológicos que sempre estiveram disponíveis aos educadores/educadores ambientais, têm papel significativo na propagação de valores sustentáveis.

No sentido de uma EA Profunda (RIBEIRO, 2013), o investimento no comportamento virtuoso requer não apenas mudanças de valores distorcidos, mas, em primeiro lugar, a percepção associada desses valores distorcidos, dessas marcas do ego (self) e personalidade (ALMAAS, 2013; BABA, 1994; JUNG, 2011) e, sobretudo, do ímpeto à mudança, o que resulta na consciência sobre si, cujo percurso leva ao autoconhecimento (RIBEIRO; SCHWARTZ, 2017). Esse caminho também é apontado por Hubbard (2012) e leva a uma evolução da consciência, cujos reflexos recaem sobre a sustentabilidade planetária.

Esta jornada rumo à transformação pode ter como excelentes auxiliares os filmes. Em Psicologia Positiva dos Filmes: usando filmes para construir virtudes e características fortes, Niemiec e Wedding (2013, p. 19, tradução nossa) convidam à reflexão, ao apresentarem ao leitor duas frases, uma de autoria de Ingmar Bergman, "Nenhuma arte perpassa a nossa consciência, da forma com que um filme faz, e vai diretamente até nossos sentimentos, atingindo a profundidade dos quartos escuros da nossa alma". E outra de Walt Disney, "então, ao planejar um filme, não pensamos em adultos e não pensamos em crianças, mas apenas naquele lugar puro e intocado dentro de todos nós que o mundo talvez tenha feito esquecer e que o filme pode ajudar a resgatar" (NIEMIEC; WEDDING, 2013, p. 29, tradução nossa).

Estes resultados apontam para a profundidade da chamada sétima arte na tarefa de alcançar o mais íntimo, intocado e puro, onde reside a essência humana e suas virtudes. Conhecer a si mesmo é tão importante quanto compreender as dinâmicas dos ecossistemas, uma vez que alguém pode saber muito sobre muita coisa, mas pode não saber nada sobre si ou apenas pensar que sabe. São os personagens maravilhosos e as situações nas quais estão inseridos que nos transportam para dimensões mais profundas na existência e lá são plantadas informações que se transformam em emoções, dão origem a pensamentos e se tornam valores e virtudes que, por sua vez, se materializam como padrões comportamentais novos e sustentáveis.

Este pode ser um dos caminhos para a efetivação de mudanças profundas, as quais podem alterar padrões antigos e insustentáveis de comportamento e colaborar para a construção de sociedades felizes e sustentáveis. E, hoje, está à distância de um clic. 


\section{Referências}

ALMAAS, A.H. The pearl beyond price: integration of personality into being: an object relations approach. Boston: Shambhala, 2013.

ALVES, M. G. D.; SORRENTINO, M. Felicidade e seu papel nos processos educadores: um diálogo necessário na busca de indicadores de sustentabilidade socioambiental. In: ENCONTRO NACIONAL DA ANPPAS, 5., 2010, Florianópolis. Anais [...]. Florianópolis: ANPPAS, 2010. Disponível em: https://bit.ly/2MmyVXh. Acesso em: 2 out. 2016.

ARAÚJO, U. F.; PUIG, J. M. Educação e valores: pontos e contrapontos. São Paulo: Summus, 2007.

BABA, S. Shadana: o caminho interior. Rio de Janeiro: Record, 1994.

BLASCO, P. G.; GAlliAn, D. M. C.; RONCOLETTA, A. F. T.; MORETO, G. Cinema para o estudante de medicina: um recurso afetivo/efetivo na educação humanística. Revista Brasileira de Educação Médica, Rio de Janeiro, v. 29, n. 2, p. 119-128, 2005.

BONOTTO, D. M. B.; CARVALHO, M. B. S. S. Educação ambiental e valores na escola: buscando espaços, investindo em novos tempos. São Paulo: Ed. Unesp, 2016.

BRASIL. Ministério do Meio Ambiente. Programa Nacional de Educação Ambiental: ProNEA. Brasília, DF: Ministério do Meio Ambiente, 2005.

DOWBOR, L. Tecnologias do conhecimento: os desafios da educação. Petrópolis: Vozes, 2013.

FAY, M. P.; PROSCHAN, M. A. Wilcoxon-Mann-Whitney or t-test? On assumptions for hypothesis tests and multiple interpretations of decision rules. Statistics Surveys, Bethesda, v. 4, p. 1-39, 2010.

FERREIRA, É. G. S.; LIMBERGER, D. C. H. Vídeo-documentário como ferramenta sensibilizadora de educação ambiental, nos Butiazais de Tapes (RS). Revista Eletrônica Científica da UERGS, Bagé, v. 3, n. 4, p. 764-775, 2017.

FRAGA, L. A.; BONOTTO, D. M. B. Educação ambiental e valores: a valorização do encontro com o outro. Pesquisa em Educação Ambiental, Rio Claro, v. 11, n. 1, p. 37-51, 2016.

GIL, A. C. Métodos e técnicas de pesquisa social. São Paulo: Atlas, 2008.

HUBBARD, B. M. Emergence: the shift from ego to essence. Newburyport: Hampton Roads Publishing, 2012.

JUNG, C. G. O homem e seus símbolos. Rio de Janeiro: Nova Fronteira, 1992.

JUNG, C. G. O eu e o inconsciente. Rio de Janeiro: Vozes, 2011.

LINS, S. L. B., CAVALCANTI, C. M.; FARIA, R. C. P. Valores humanos e comportamento ecológico de universitários brasileiros e portugueses. Educamazônia Educação Sociedade e Meio Ambiente, Humaitá, v. 4, n. 1, p. 42-74, 2011.

MARQUES, A. R.; REIS, P. Producción y difusión de vídeos digitales sobre contaminación ambiental. Estudio de caso: activismo colectivo basado en la investigación. Revista Eureka sobre Enseñanza y Divulgación de las Ciencias, Cádiz, v. 14, n. 1, p. 215-226, 2017.

MARTINELLI, M. Conversando sobre educação em valores humanos. São Paulo: Peirópolis, 1999. 
MCLUHAN, M. The Gutemberg galaxy: the making of typographic man. Toronto: University of Toronto Press, 1962.

MINAYO, M. C. S.; SANCHES, O. Quantitativo-qualitativo: oposição ou complementaridade? Caderno de Saúde Pública, Rio de Janeiro, v. 9, v. 3, p. 239-262, 1993.

MORAES, M. A. C.; ESCOTT, C. M.; PIZZATO, M. C. O papel da mídia publicitária na formação da identidade popular: de reguladora a regulada. Ciências \& Letras, Porto Alegre, n. 49, p. 157-170, 2011.

MORENO, J. C. A internet em McLuhan, Baudrillard e Habermas. Observatório (OBS*), Lisboa, v. 7, n. 3, p. 59-77, 2013.

MYERS, D. G. Exploring psychology. New York: Macmillan, 2004.

NIEMIEC, R. M.; WEDDING, D. Positive psychology at the movies: using films to build virtues and character strengths. Boston: Hogrefe Publishing, 2013.

O'BRIEN, C. et al. Sustainable happiness and well-being: Future directions for positive psychology. Psychology, Cidade, v. 3, n. 12, p. 1196, 2012.

ODOUL, M. Diga-me onde dói e eu te direi por quê. Rio de Janeiro: Elsevier, 2003.

ORTIGOSA, S. A. G.; LOMBARDO, M. A. No "clima" do consumo: implicação do consumo nas mudanças climáticas globais. Rio Claro: Divisa Gráfica e Editora, 2011.

PETERSON, C.; SELIGMAN, M. E. P. Character strengths and virtues: a handbook and classification. New York: Oxford University Press, 2004.

PAYNE, D. M. Learning from health care exemplars: how the best produce extraordinary results. 2015. Dissertação (Mestrado em Psicologia Positiva Aplicada) - University of Pennsylvania, Philadelphia, 2015. Disponível em: https://bit.ly/2qimdjC. Acesso em: 28 set. 2016.

PLATÃO. Fédon. São Paulo: Editora Abril Cultural, 1999. (Coleção Os Pensadores)

RIBEIRO, I. C. Sementes para o futuro: educação ambiental de Corpo\&Alma: trabalhando sentimentos e valores numa experiência com Agenda 21 Escolar. Ribeirão Preto: São Francisco, 2005.

RIBEIRO, I. C. Educação ambiental de corpo\&alma. In: SEABRA, G. (Org.). Educação ambiental no mundo globalizado: uma ecologia de riscos, desafios e resistência. João Pessoa: Ed. UFPB, 2011. p. 3964.

RIBEIRO, I. C. As emoções, a felicidade e um planeta chamado água. In: SEABRA, G. (Org.). Educação ambiental: conceitos e aplicações. João Pessoa: Ed. UFPB, 2013. p. 151-169.

RIBEIRO, I. C.; CARVALHO, M. B. S.; MATOS, F. A. Pedagogia do alento: paz e sustentabilidade para o século 21. In: PERES, A. N.; VIEIRA, R. (Orgs.). Educação, justiça e solidariedade na construção da paz. Leiria: APAP, 2010. p. 264-282.

RIBEIRO, I.C.; SCHWARTZ, G. M. Questionário FIS: felicidade interna sustentável. Laboratório de Estudos de Lazer da Universidade Estadual Paulista, Rio Claro, 2014. Disponível em: https://bit.ly/2MmWz60. Acesso em: 12 out. 2019.

RIBEIRO, I. C.; SCHWARTZ, G. M. Valores em transformação: por uma felicidade sustentável. São Carlos: Rima, 2017. 
RICHARDSON, R. J. Pesquisa social: métodos e técnicas. São Paulo: Atlas, 2007.

RUSCHEINSKY, A. Contribuições das ciências sociais em face dos entraves à educação para sociedades sustentáveis. Revista Portuguesa de Educação, Braga, v. 23, n. 1, p. 29-54, 2010.

SILVA, M. G. C. Religião e sustentabilidade: meio ambiente e qualidade de vida. Paralellus, Recife, v. 4, n. 8, p. 175-186, 2013.

TRAJBER, R.; COSTA, L. (Org.). Avaliando a educação ambiental no Brasil: materiais audiovisuais. São Paulo: Peirópolis, 2001.

TURNER, N.; BARLING, J.; ZACHARATOS, A. Positive psychology at work. In: SNYDER C. R.; LOPES, S. J. (Eds.). Handbook of positive psychology. New York: Oxford University Press, 2002. p. $715-728$.

VITERI, F.; CLAREBOUT, G.; CRAUWELS, M. Children's recall and motivation for an environmental education video with supporting pedagogical materials. Environmental Education Research, New York, v. 20, n. 2, p. 228-247, 2014.

ZAN VIEIRA, F.; ROSSO, A. J. O cinema como componente didático da educação ambiental. Revista Diálogo Educacional, Curitiba, v. 11, n. 33, p. 547-572, 2011.

ZWEIG C.; ABRAMS, J. (Eds.). Encuentro con la sombra: el poder del lado oscuro de la naturaleza humana. Barcelona: Editorial Kairós, 2002. 